\title{
Bandwidth Improvement of Microstrip Crossed Monopole Antenna
}

\author{
Vipin Singh \\ Dept. Electronics \& Communication \\ SIRT BHOPAL
}

\author{
Krishna Chauhan \\ Dept. Electronics \& Communication \\ SIRT BHOPAL
}

\begin{abstract}
A compact size low profile microstrip-fed crossed monopole antenna for ultra wideband communication is presented. The impedance bandwidth of a microstrip crossed monopole antenna has increased with a suitable dimension of ground plane and rectangular patch. The aim of this paper is to improved bandwidth and return loss of a Crossed Monopole Microstrip patch antenna and study the effect of antenna and ground dimension length (L), width (W) and substrate parameters relative dielectric constant, substrate thickness on radiation parameters of bandwidth. Low dielectric constant substrates are generally preferred for maximum radiation. The crossed monopole shows the return loss of $-10 \mathrm{~dB}$ over ultra wideband frequency range $(3.3-13.6 \mathrm{GHz})$ while maintain the stability in radiation pattern. The simulation software (CST) obtains the effect of the parameter on the performance of the antenna.
\end{abstract}

\section{Keywords}

Wideband Antenna, Microstrip Feed, Monoploe Antenna, Return Loss .

\section{INTRODUCTION}

Ultra wideband communication (UWB) technology is the most expecting hopeful for the future. It has promoted the research worker to innovate different ultra wideband antennas. It main advantage is short distance radio communication, high speed data communication, low power consumption. In 2002 Federal communication commission (FCC) eject the officially allocated frequency spectrum from 3.1 to $10.6 \mathrm{GHz}$. Therefore ultra wideband communication system has gained great attention for both academic and industry [1]. The Monopole antenna is widely used for ultra wideband communications due to their magnetic features of allow bandwidth, simple structure and omnidirectional radiation pattern [2-4]. However, the microstrip patch antenna is favored with ground plane due to its light weight, small size, low cost and ease of integration with printed circuit board. This paper presents a simple, easy to fabricate Microstrip-fed Crossed Monopole antenna with cross plate and defected ground plane is used which shows improved result for ultra wideband communication than [2]. Different microstrip patch antennas of various shapes are designing for this purpose [58]. In the presented paper, this idea is implementing for the improved bandwidth and return loss of microstrip crossed monopole antenna. The novel demonstrates that the optimal design of this type antenna can achieve UWB performance. The UWB antenna is characterized by impedance matching and stable radiation pattern over the bandwidth $(3.3-13.6$ $\mathrm{GHz}$ ). The return loss has improved by using the defect in ground plane [9] .The electromagnetic software Computer Simulation Technology (CST) used for the simulation.

\section{ANTENNA DESIGN}

The given microstrip-fed crossed monopole antenna which consist of a simple rectangular patch of dimension
$15 \times 20 \mathrm{~mm} 2$ and ground plane of dimension $24 \times 15 \mathrm{~mm} 2$. The antenna has fabricated on the dielectric substrate FR4 of thickness $1 \mathrm{~mm}$ and relative permittivity of 4.3. the impedance of microstrip feed line is $50 \Omega$ which is $\square$ printed on the same side of the substrate. The width of the strip of microstrip antenna has fixed to $2 \mathrm{~mm}$ to find the characteristic impedance of $50 \Omega$. The length of ground plane $\mathrm{G} 1=15 \mathrm{~mm}$ is printed on the opposite side of the substrate and covers only a part of the microstrip feed line and the difference between the ground plane and patch is $1 \mathrm{~mm}$. The patch length and patch width are adjusted to find the desired lower frequency end. The length of the substrate is $32 \mathrm{~mm}$ as shown in Fig. 1. The cross patch has designed to have a resonance near the upper end of the desired spectrum range. The combined effect of the crossed plate and defected ground plane shows the return loss over a wide frequency range. The impedance bandwidth of the antenna fine-tuned by suitably choosing the the monopole dimensions, ground plane size, feed gap etc. The rectangular patch and ground plane are printed on the opposite side of an in expensive dielectric substrate FR4 glass epoxy of $(€ \mathrm{r})=$ 4.3.and the defected ground plane dimension is $1 \mathrm{~mm} 2$ cutting area at the strip location.

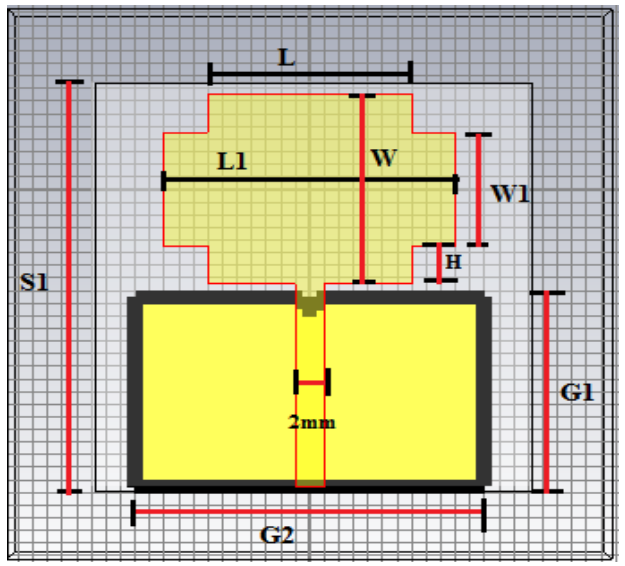

Fig-1 Geometry of proposed antenna

\section{SIMULATION RESULTS}

The simulated results are using CST Microwave Studio package. Figure -2 shows the return loss versus frequency plot for different ground plane widths (G1) of rectangular microstrip crossed monopole for fixed length L \& Next the ground plane dimensions are fixed \& the rectangular patch lengths are varied. Figure $3-5$ shows the return loss versus frequency plots for various lengths, width and the cross plate and ground plane position. The simulated data of optimal dimensions of the microstrip crossed monopole antenna are chosen . (Figure 2 - 5). The VSWR curve represented in Fig.7 and the efficiency has shown in Fig.6. The current distributions at different frequencies for the optimal design of an antenna of simulated data are presented in Fig.8. The radiation patterns of the crossed monopole at different 
frequencies are presented in Figure 8. The prototype antenna dimensions are given in the table.

\begin{tabular}{|c|c|}
\hline PARAMETER & DIMENSIONS \\
\hline S1 & $32 \mathrm{~mm}$ \\
\hline $\mathrm{G} 1$ & $15 \mathrm{~mm}$ \\
\hline $\mathrm{G} 2$ & $28 \mathrm{~mm}$ \\
\hline $\mathrm{T} 1$ & $2 \mathrm{~mm}$ \\
\hline $\mathrm{H} 1$ & $16 \mathrm{~mm}$ \\
\hline $\mathrm{L} 1$ & $14 \mathrm{~mm}$ \\
\hline $\mathrm{L} 1$ & $20 \mathrm{~mm}$ \\
\hline $\mathrm{W} 1$ & $15 \mathrm{~mm}$ \\
\hline $\mathrm{H}$ & $9 \mathrm{~mm}$ \\
\hline
\end{tabular}

The return loss of simulated results using CST shown .

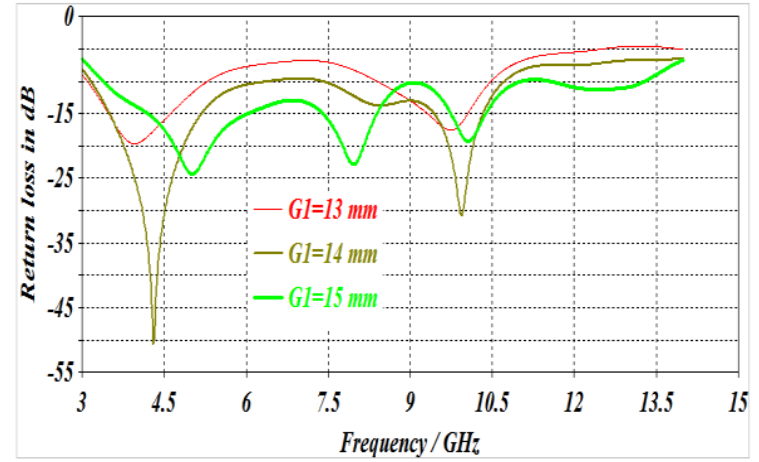

Fig.2 The return loss for various ground plane widths (G1) plot of (Fig.1).

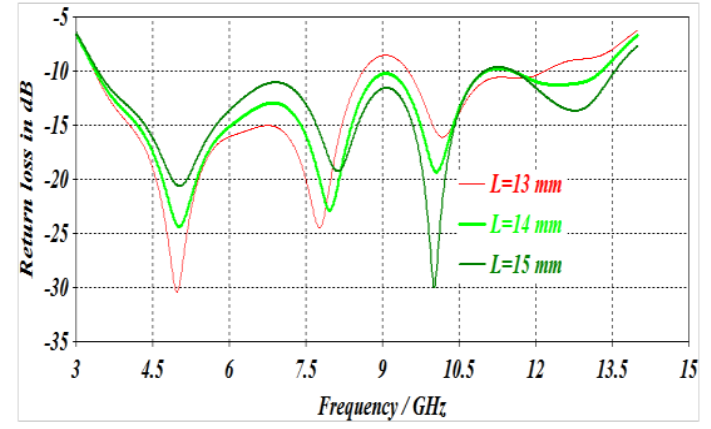

Fig.-3 The return loss for various cross plate lengths $(\mathrm{L})$ plot of (Fig.1).

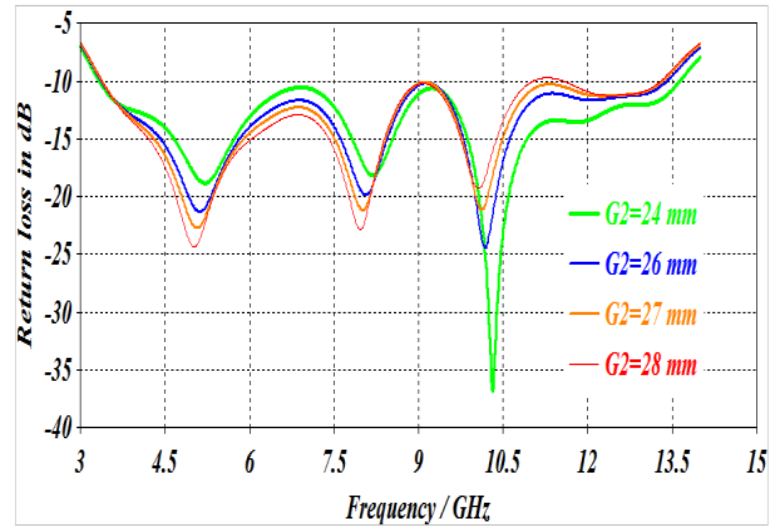

Fig.-4 The return loss for various ground plane lengths (G2) plot of (Fig.1).

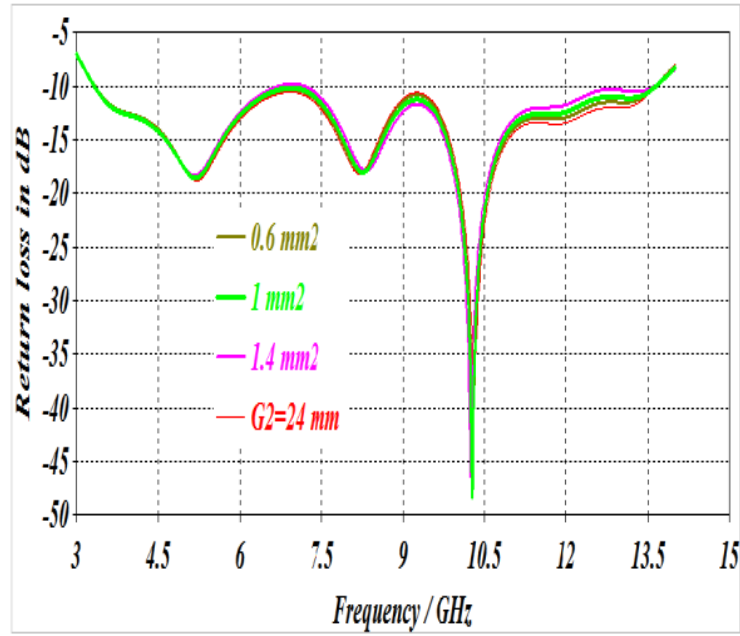

Fig.-5 The return loss due to defect in ground plane at the strip location plot of (Fig.1 )

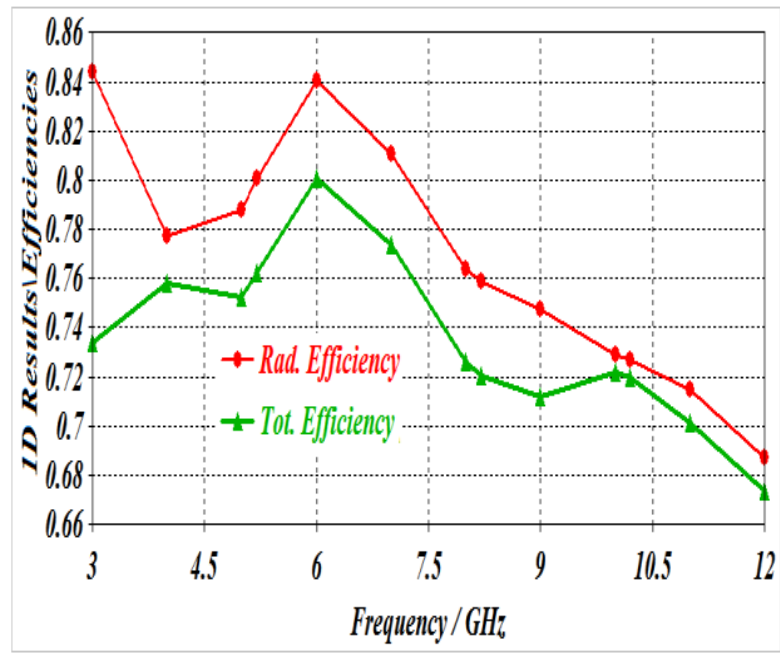

Fig.-6 The efficiency plot.

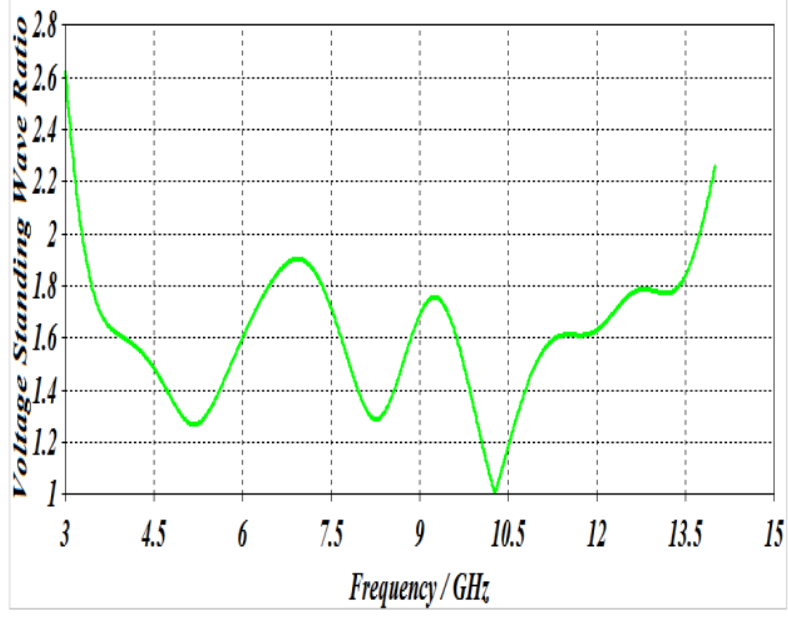

Fig.-7 The VSWR plot. 

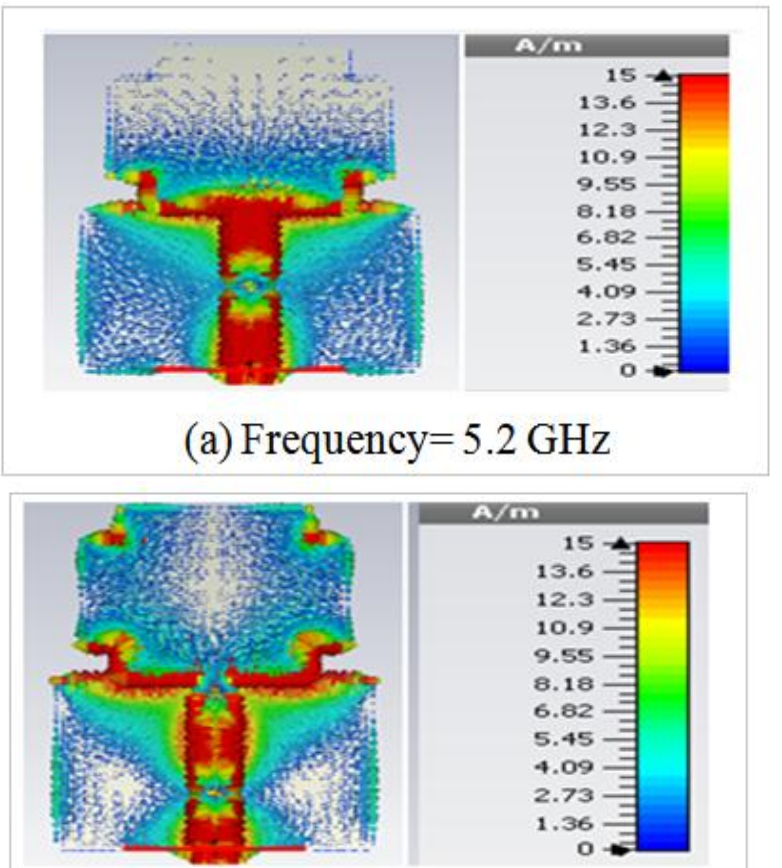

(b) Frequency $=8.2 \mathrm{GHz}$

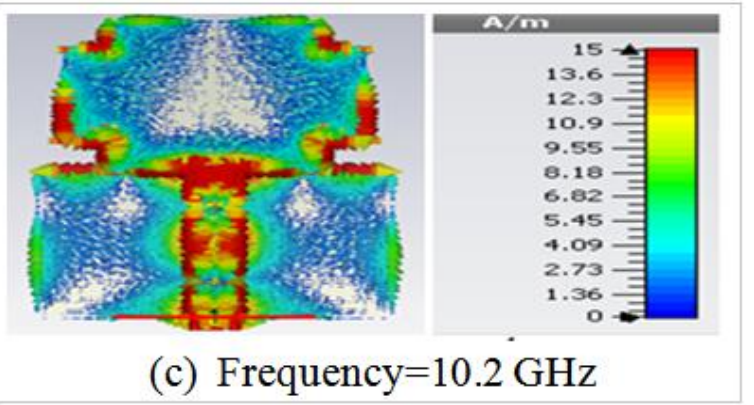

Fig.-8 The current distributions on the cross plate and ground plane at different frequencies plot.

\section{DISCUSSIONS}

The data of the rectangular crossed monopole (Fig. 2) shows return loss plot which depends on the first resonance frequency on the antenna ground widths (G1). The variation of lengths of the cross plate \& the variation of the lengths of the ground plane appreciably increases the impedance bandwidth. The optimum design of an antenna to find the desired return loss of $-10 \mathrm{~dB}$ over the UWB frequency range has chosen from Fig. $3-4$. The microstrip crossed monopole antenna's ground plane tunes out the reactive component of the input impedance of a simple rectangular patch and increases the bandwidth. The ground plane size affects the impedance bandwidth of the antenna shows in Fig.4. The impedance matching circuit of ground plane serves as and tunes the input impedance of the antenna. Fig. 5 shows the return loss curves due to defect in ground plane at the strip location. The cutting area of the ground plane at the strip location is $1 \mathrm{~mm} 2$ which increases the return loss and the Return loss is $-48.44 \mathrm{~dB}$ at $10.2 \mathrm{GHz}$. The return loss represents the amount of power, which is reflected back due to impedance mismatching. Fig.6 shows the plot of linear efficiency, which shows that at $10.2 \mathrm{GHz}$ the total efficiency is equal to radiation efficiency means at $10.2 \mathrm{GHz}$ the loss, is very less. Fig. 7 shows the plot of VSWR which is also like return loss. It is the measure that how mismatch is the antenna impedance with input impedance. Which are approximately less than 2 at the frequency range $(3.3-13.6)$ and which is approximate equal to 1 at $10.2 \mathrm{GHz}$. Fig. 8 shows that the current has distributed mainly along the two side edges of the cross plate, which causes most of the radiation. The concentration of current increases on the cross arms at higher end frequency of the operating band. The current distribution patterns corresponding to the fundamental, second order and third order harmonics respectively shows in Fig. 8 (a) - (c). Thus, the use of the ground plane adds modes of higher resonances causing an increase in the impedance bandwidth. The current distribution on the ground plane has main portion on the close to the monopole and hence this part of the ground plane takes part in radiation and the data of current distribution shows in unit A/m. Fig.9 shows the plot of smith chart, which shows that impedance of microstrip patch antenna, is around $50 \Omega$. The simulated data shows $-10 \mathrm{~dB}$ return loss bandwidth over the UWB frequency range. Here the term bandwidth in antenna means the usable frequency range with reasonable performance, which is represented in percentage, and the bandwidth is $122 \%$.

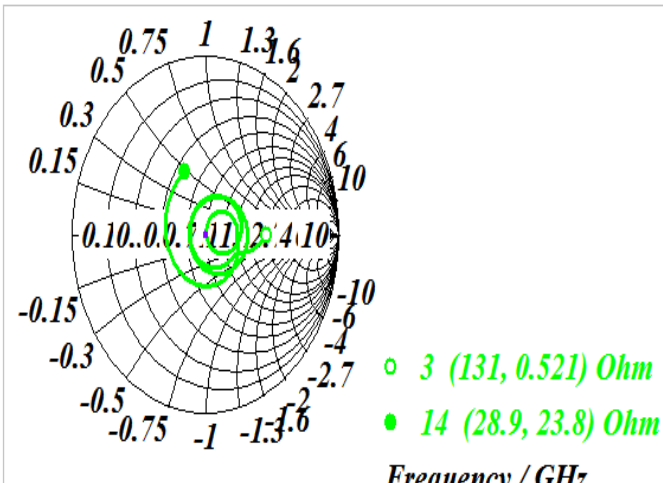

Frequency $/ \mathrm{GHz}$

Fig.-9 Smith chart plot.

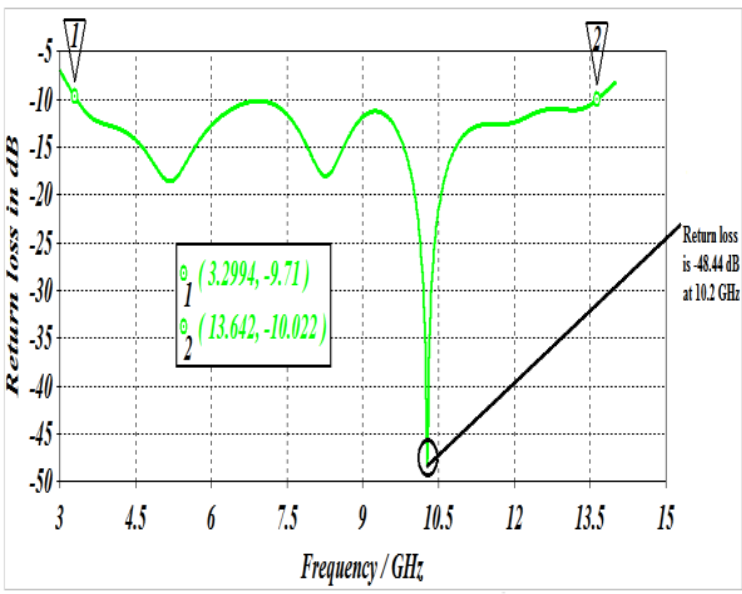

Fig.-10 Improved bandwidth \& Return loss.

\section{CONCLUSION}

The small size microstrip-fed UWB microstrip crossed monopole antenna have been successfully demonstrated in this paper. The simulated results for the return loss describes that the wide bandwidth approximate $122 \%$ and return loss $48.44 \mathrm{~dB}$ over ultra wideband frequency range can be achieved by suitably adjusting the modified ground plane \& antenna parameters of the crossed monopole antenna. This 
antenna can be used in ultrawideband communication. It can also used in satellite communication and other various applications

\section{REFERENCES}

[1]. Federal communication commission"First order and report: Revision of part 15of the Commission's rules regarding UWB transmissions systems,"Apr, 2002.

[2]. Saraswati Gosh and Binay Kumar ," Design of microstrip crossed monopole antenna for ultra wideband communication", 978-1-4673-2272-0/12/ IEEE 2012.

[3]. S.Ghosh,'Design of planer crossed monopole antenna for Ultra wideband communication," IEEE Antennas Wireless Propagation Letters, vol.10, pp.548-551, 201[1]

[4]. E. Lee, P. S. Hall, and P. Gardner, "Compact wideband planar monopole antenna," Electronics Letters, vol. 35, no. 25, pp. 2157-2158, Dec. 1999.

[5]. ] K. Chung, T. Yen, and J. Choy, "Wideband CPW-fed monopole antenna with parasitic elements and slots,"
Electronics Letters, vol. 40, no. 17, pp. 1038-1040, Aug. 2004.

[6]. J. Liang, C. C. Chiau, X. Chen, and C. G. Perini, "Study of a Printed Circular Disc Monopole Antenna for UWB Systems," IEEE Transactions on Antennas and Propagation, vol. 53, pp. 3500 -- 3504, November 2005.

[7]. Ahmed Khidre, Kai-Fong Lee, Fan Yang, and Atef Z. Elsherbeni "Circular Polarization Reconfigurable Wideband E-Shaped Patch Antenna for Wireless Applications",IEEE Transactions on Antenna and Propagation, vol. 61, no.2,pp.960-965, February 2013

[8]. Wenwen Yangand JianyiZhou,"Wideband Low-Profile Substrate Integrated Waveguide Cavity-Backed EShaped Patch Antenna", IEEE Transactions on Antenna and Propagation , vol.12,2013

[9]. Kaushik Mandal and Partha Prtim Sarkar "High Gain Wide-Band U-Shaped Patch Antennas With Modified Ground Planes", IEEE Transactions on Antenna and Propagation ,vol. 61, no.4,pp.2279-2282,April 2013 